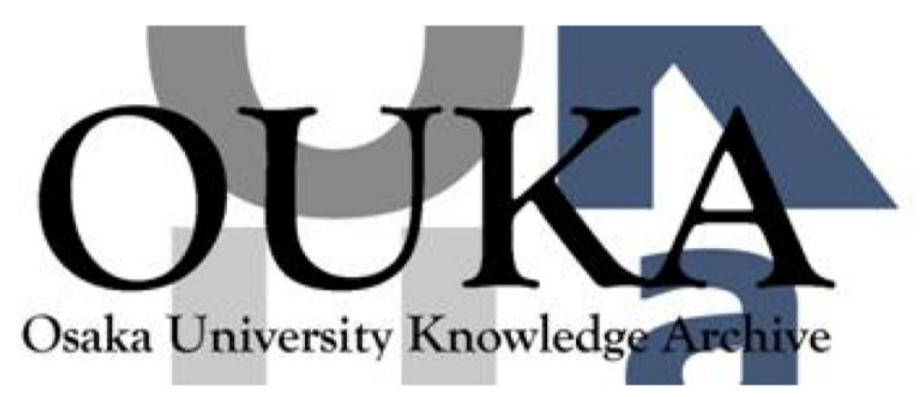

\begin{tabular}{|c|c|}
\hline Title & $\begin{array}{l}\text { GHz-range resonant ultrasound spectroscopy for } \\
\text { a free-standing nano film studied by picosecond } \\
\text { ultrasonics }\end{array}$ \\
\hline Author(s) & $\begin{array}{l}\text { Nagakubo, Akira; Adachi, Kanta; Nishihara, } \\
\text { Tokihiro et al. }\end{array}$ \\
\hline Citation & $\begin{array}{l}\text { Applied Physics Express. 13(1) p. 016504-1- } \\
\text { p. 016504-4 }\end{array}$ \\
\hline Issue Date & $2019-12-19$ \\
\hline oaire:version & AM \\
\hline URL & https://hdl. handle. net/11094/84530 \\
\hline rights & $\begin{array}{l}\text { ब } 2019 \text { The Japan Society of Applied Physics. } \\
\text { This Accepted Manuscript is available for reuse } \\
\text { under a Creative Commons Attribution- } \\
\text { NonCommercial-NoDerivatives } 4.0 \text { International } \\
\text { License after the } 12 \text { month embargo period } \\
\text { provided that all the terms of the license are } \\
\text { adhered to. }\end{array}$ \\
\hline Note & \\
\hline
\end{tabular}

Osaka University Knowledge Archive : OUKA

https://ir. Library. osaka-u. ac. jp/

Osaka University 


\title{
GHz-range resonant ultrasound spectroscopy for a free-standing nano film studied by picosecond ultrasonics
}

\author{
Akira Nagakubo ${ }^{*}$, Kanta Adachi ${ }^{2}$, Tokihiro Nishihara ${ }^{3}$, and Hirotsugu Ogi ${ }^{1 \dagger}$ \\ ${ }^{1}$ Graduate School of Engineering, Osaka University, Suita, Osaka 565-0871, Japan \\ ${ }^{2}$ Graduate School of Arts and Science, Iwate University, Morioka, Iwate 020-8551, Japan \\ ${ }^{3}$ Taiyo Yuden Co., Ltd., Akashi, Hyogo 674-8555, Japan
}

\begin{abstract}
Progress in the wireless communication requires higher frequency bandpass filters, and the bulk acoustic-wave filter is especially the key device for the $\mathrm{GHz}$-range communication. Its resonance frequencies depend on the elastic constants of individual layers, but it is never straightforward to measure them. In this study, we apply resonant ultrasound spectroscopy to a $\mathrm{GHz}$-range freestanding $\mathrm{AIN} / \mathrm{Ru} / \mathrm{Cr}$ resonator to simultaneously determine the elastic constant of each layer. Using picosecond ultrasonics, we measure free-vibration resonance frequencies up to $\sim 70 \mathrm{GHz}$ and inversely determine it. The obtained values are reasonable as thin films elasticity, confirming the applicability of the proposed method.
\end{abstract}

With the progress of wireless communication, surfaceacoustic-wave (SAW) filters and bulk-acoustic-wave (BAW) filters have been keenly studied. These filters are required to operate at high frequencies with high stability against temperature change, broad and tunable band, and low energy loss. Communication frequency and the band width of SAW filters can be controlled by the pattern and alignment of the interdigital transducers (IDT). To make higher-frequency SAW filters, higher-velocity substrates and leakage SAW modes have attracted attention $^{1-3)}$ and their energy loss has been improved. ${ }^{4-8)}$ However, as the frequency increases, IDT affects surfacewave properties $^{9)}$ and wave-propagation modes become complicate. ${ }^{10)}$ Limitation of IDT width prevents us from making higher-frequency SAW filters.

On the other hand, the frequency of BAW filters is principally inversely proportional to the film thickness, allowing us to make much higher-frequency filters. ${ }^{11-16)}$ One of problems for the BAW filter is energy loss: it comprises piezoelectric and metallic thin films, and the vibration energy can easily propagate into adjacent layers and the substrate. The energy leakage can be minimized by a Bragg reflector, which is a multilayer comprising alternate high and low acoustic impedance materials with the quarter-wavelength thickness. ${ }^{17-19)}$ Another way to enhance the quality factor is to make a free-standing film by removing the BAW filter from the substrate, which makes the energy leakage into the substrate negligible.

Because the BAW filter uses the longitudinal throughthickness resonance, the longitudinal-wave elastic constant along the film-thickness direction in each layer is the key parameter for designing it. However, thin films usually exhibit different elasticity from bulk states, depending on their thickness and deposition conditions, ${ }^{20-22)}$ and it is improper to use the elastic constants of corresponding bulk materials.

In this study, we propose $\mathrm{GHz}$-range resonant ultrasound spectroscopy (RUS) using picosecond ultrasonics with two femtosecond pulse lasers to determine the elas-

\footnotetext{
*E-mail: nagakubo@prec.eng.osaka-u.ac.jp

†E-mail: ogi@prec.eng.osaka-u.ac.jp
}

(a) Cross-section schematic view

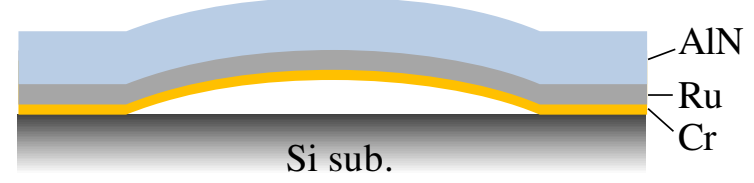

(b) Top picture view

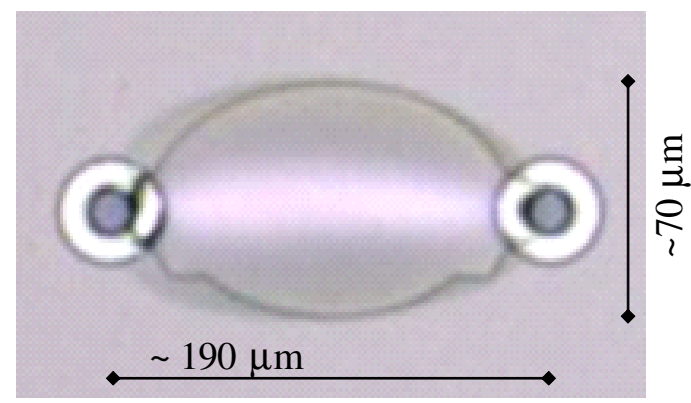

Fig. 1. (Color online) (a) Cross-section schematic view and (b) top picture view of the free-standing $\mathrm{AlN} / \mathrm{Ru} / \mathrm{Cr}$ film.

tic constants of nm-order multilayers. We fabricate freestanding $\mathrm{AlN} / \mathrm{Ru} / \mathrm{Cr}$ multilayer films as a model BAW resonator, and irradiate it with a femtosecond light pulse to excite many vibration modes. We successfully observe the reverberating signal after the excitation up to 12.5 ns by combining the mechanical delay line (MDL) and a synchro-lock system for synchronizing the two pulse lasers. The fast Fourier transform (FFT) provides the resonance spectrum, showing resonance frequencies up to $\sim 70 \mathrm{GHz}$, which are used to determine the elastic constant of each layer by an inverse calculation. We calculate the elasticity contribution to the resonance frequency and strain-energy distribution for each mode and discuss the inverse-calculation uncertainty in deducing the elastic constants.

We deposit $\mathrm{Cr}$ and $\mathrm{Ru}$ films by the $\mathrm{DC}$ magnetron sputtering method at room temperature, and deposit a highly $c$-axis oriented AIN film by the electron cyclotron resonance sputtering method in an $\mathrm{Ar} / \mathrm{N}_{2}$ mixture atmosphere using a pure $\mathrm{Al}$ target. ${ }^{23)}$ Thicknesses of $\mathrm{AlN}, \mathrm{Ru}$, 
(a)

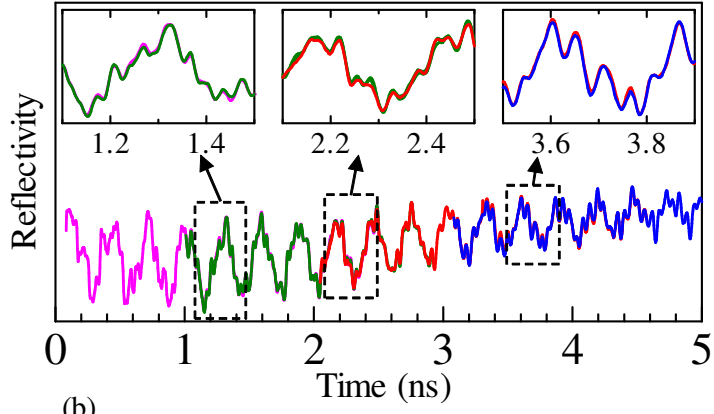

(b)

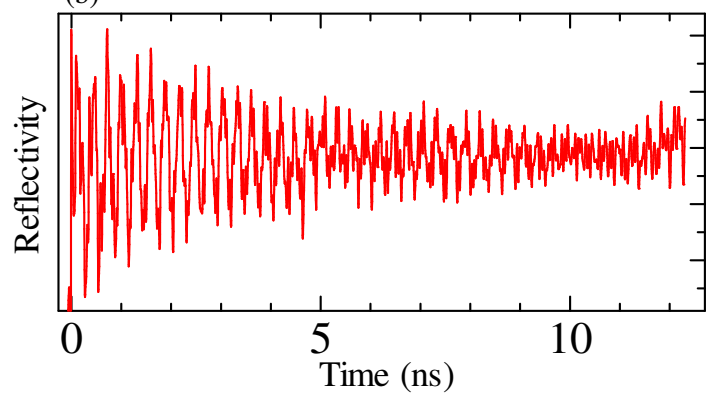

(c)

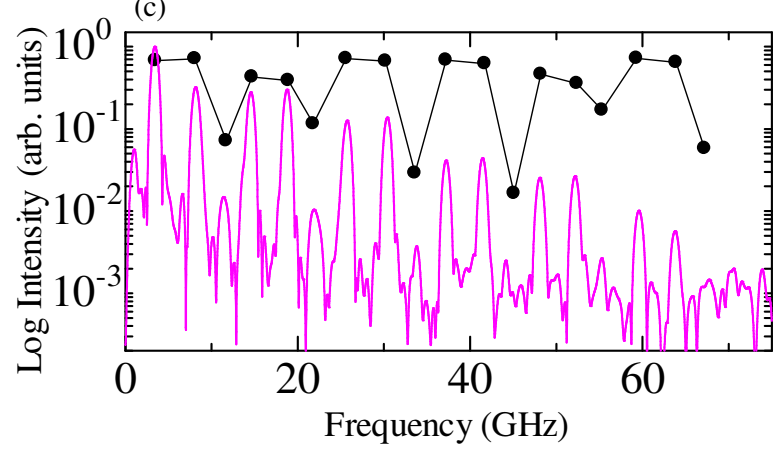

Fig. 2. (Color online) (a) Measured film resonances with the 2.6-ns mechanical delay line. We change the initial delay time by the synchro-lock system, which are shown by different-color lines. (b) Full-time-range resonance constructed with 12 scan data. (c) A typical FFT spectrum of the resonance. Solid circles show the detection intensity calculated from the strain of the $\mathrm{Ru}$ surface.

and $\mathrm{Cr}$ layers are 1000, 200, and $100 \mathrm{~nm}$, respectively. We evaluate the crystal orientation by $\mathrm{x}$-ray diffraction, cross-section transmission-electron-microscope image, and the electron diffraction pattern, which indicates that $\mathrm{Ru}$ and AlN have $c$-axis oriented structure. ${ }^{14,24,25)}$ Then, we fabricate 14 dome-shape free-standing films ${ }^{26)}$ in a $3 \times 5 \mathrm{~mm}^{2}$ chip, whose structure is shown in Fig. 1 . We can not electrically evaluate their resonance properties because of no top electrodes. Resonance frequency of a corresponding 1.1- $\mu \mathrm{m}$ AlN FBAR is about $2 \mathrm{GHz} .^{24,27)}$ To determine the elastic constants of individual layers, we apply the RUS method to a GHz range: The conventional RUS method has been adopted to study the elasticity of a solid using its $\mathrm{kHz}$ to $\mathrm{MHz}$ resonance frequencies. $^{28)}$ By comparing the measured and calculated resonance frequencies, we can determine all independent elastic constants from a single measurement. ${ }^{29-32)}$ Here, we use picosecond ultrasonics ${ }^{33,34)}$ to excite and detect $\mathrm{GHz}$-range resonance frequencies of the film. We use two titanium/sapphire femtosecond pulse lasers, whose wave- length, repetition rate, and pulse duration time are about $800 \mathrm{~nm}, 80 \mathrm{MHz}$, and $150 \mathrm{fs}$, respectively. We synchronize them within $\sim 50 \mathrm{fs},{ }^{35)}$ and their initial delay time can be changed within the repetition period of $12.5 \mathrm{~ns}$, which enables us to observe long time oscillations with a short MDL. Our MDL in the pump light path comprises two corner reflectors and a 200-mm stage controller, corresponding to $\sim 2.6$-ns delay time. We modulate the pump light pulses at $100 \mathrm{kHz}$. The wavelength of probe light is converted into $400 \mathrm{~nm}$ by a second harmonic generator. The pump and probe light pulses normally enter the specimen through an apochromat objective lens of 150 magnification. Using a microscope, we observe the film surface and the light positions through the objective lens. Spot diameters are about $1-2 \mu \mathrm{m}$ on the specimen surface, and we focus both lasers on the centers of the free-standing films. The laser powers of pump and probe light are about 15 and $10 \mathrm{~mW}$, respectively, which does not affect measured properties due to laser-irradiation heating. Specimen temperature is about 295-296 K. In this measurement, we do not measure and consider the temperature dependence of acoustic properties of the FBAR, however, our low-temperature ${ }^{36,37)}$ and high-temperature ${ }^{38)}$ measurement could evaluate it.

We measure the film resonance behavior in a long time range with a high time resolution as shown in Fig. 2(a) by combining the MDL and electrically changeable initial delay time by the synchro-lock system. We superimpose different initial-delay-time measurements, which show good agreement as shown in the inset, allowing us to measure the film resonance in the full time range of $12.5 \mathrm{~ns}$ (the repetition period of the pump light pulses) as shown in Fig. 2(b), where we use 12 scan data and subtract the background reflectivity change due to thermal diffusion. To observe the 12.5-ns time range only by an MDL, optical path length reaches $3.75 \mathrm{~m}$, which expands laser diameter and requires large space and difficult adjustment. Multi-pass MDL can save space, however, it also expands pulse duration time, resulting in a low time resolution of $\sim 1$ ps. ${ }^{39-41)}$ The asynchronous optical sampling method enables the full-timerange measurement without the long MDL. However, its time resolution is about $0.5-2.5 \mathrm{ps}^{42-44)}$ By using 1-GHz repetition-rate titanium/sapphire pulse lasers, Bartels et al. achieved the 160-230 fs time resolution only in a 1-ns time range. ${ }^{45,46)}$ On the other hand, our system enables the 12.5 ns time range measurement within the 50 fs time resolution, which is restricted by jitters in the lasers and synchro-lock system. ${ }^{35)}$ We thus succeed in measuring low-attenuation and high-frequency resonances with the sub-ps time resolution in the 12.5-ns time range.

Measured resonance frequencies exceed $60 \mathrm{GHz}$ as shown in the FFT spectrum of Fig. 2(c). We analytically calculate resonance frequencies of a free-standing multilayer using a one-dimensional continuous model. ${ }^{47,48)}$ We used mass densities of $\mathrm{AlN}, \mathrm{Ru}$, and $\mathrm{Cr}$ of their bulk values of 3260,12360 , and $7200 \mathrm{~kg} / \mathrm{m}^{3}$, respectively. The forward calculation with reported elastic constants ${ }^{49-54)}$ allows mode identification up to the 17 th mode of 63.8 $\mathrm{GHz}$. We measure four different free-standing films and determine the average frequencies and standard devia- 
Table I. Calculated and measured resonance frequencies of the $\mathrm{AlN} / \mathrm{Ru} / \mathrm{Cr}$ film and their differences.

\begin{tabular}{|c|c|c|}
\hline \multicolumn{2}{|c|}{ Resonance Frequency $(\mathrm{GHz})$} & \multirow[t]{2}{*}{ Diff. (\%) } \\
\hline Calc. & Meas. & \\
\hline 3.47 & $3.44 \pm 0.01$ & -0.99 \\
\hline 8.10 & $8.15 \pm 0.02$ & 0.64 \\
\hline 11.62 & $11.47 \pm 0.07$ & -1.25 \\
\hline 14.65 & $14.59 \pm 0.03$ & -0.45 \\
\hline 18.86 & $18.78 \pm 0.00$ & -0.44 \\
\hline 21.84 & $21.91 \pm 0.02$ & 0.34 \\
\hline 25.63 & $25.75 \pm 0.03$ & 0.46 \\
\hline 30.25 & $30.42 \pm 0.09$ & 0.56 \\
\hline 33.64 & $33.77 \pm 0.04$ & 0.37 \\
\hline 37.17 & $37.28 \pm 0.04$ & 0.28 \\
\hline 41.64 & $41.47 \pm 0.03$ & -0.41 \\
\hline 45.30 & $45.76 \pm 0.18$ & 1.00 \\
\hline 48.20 & $48.19 \pm 0.08$ & -0.04 \\
\hline 52.38 & $52.21 \pm 0.02$ & -0.32 \\
\hline 55.33 & $55.36 \pm 0.03$ & 0.06 \\
\hline 59.36 & $59.71 \pm 0.12$ & 0.59 \\
\hline \multirow[t]{2}{*}{63.84} & $63.83 \pm 0.06$ & -0.02 \\
\hline & RMS error & 0.59 \\
\hline
\end{tabular}

(a)
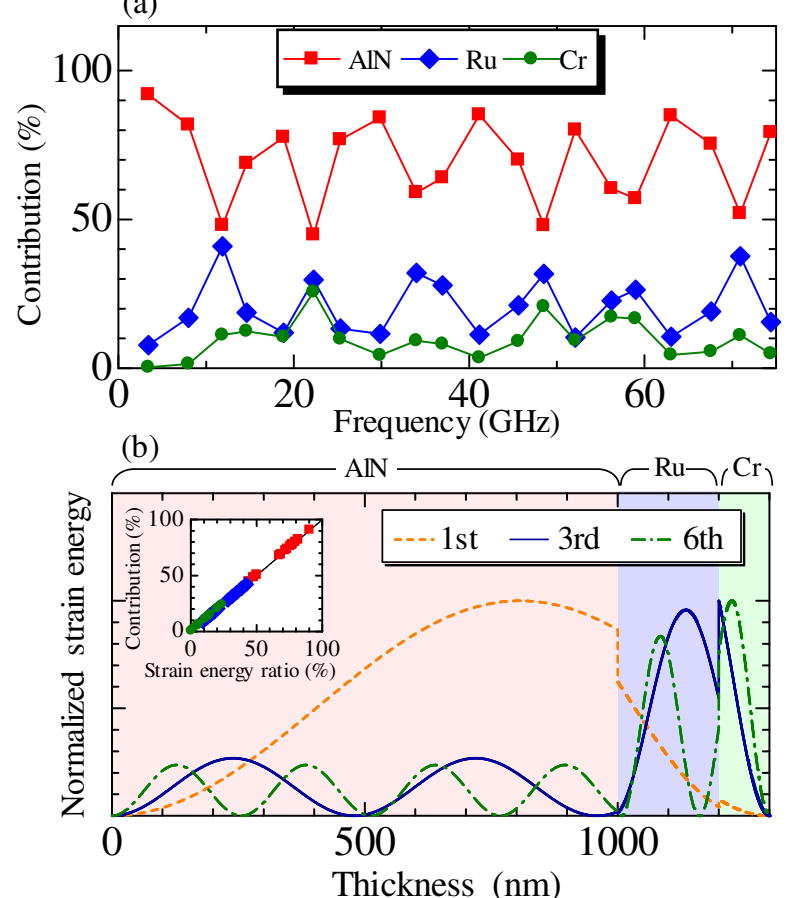

Fig. 3. (Color online) (a) Calculated contributions of the elastic constants of AlN (red square), Ru (blue diamond), and $\mathrm{Cr}$ (green circle) to the resonance frequencies. (b) Strain-energy distribution of the 1st (orange dashed), 3rd (blue solid), and 6th mode (green chain line). Inset shows the relationship between the contributions and the strain-energy ratios.

tions as shown in Table I.

Some peaks in Fig. 2(c) such as 3rd, 6th, 9th, and their harmonic modes have small intensities, and we attribute this to lower strain in the $\mathrm{Ru}$ layer near the $\mathrm{AlN} / \mathrm{Ru}$ interface because the probe light irradiates the $\mathrm{Ru}$ surface and detects its lattice strain through the photoelastic effect. We calculate the normalized strain distribution for each mode and evaluate the detection intensity from the strain of the Ru surface as shown in Fig. 2(c), which agrees favorably with the measured FFT intensity. Interestingly, these small-intensity modes are important to determine the elastic constants of $\mathrm{Ru}$ and $\mathrm{Cr}$ : We calculate the contribution $\left|2 C_{i} / f_{j}\left(\partial f_{j} / \partial C_{i}\right)\right|$ of the elastic constant $C_{i}$ of the $i$ th layer to the $j$ th resonance frequency $f_{j}{ }^{55,56)}$ as shown in Fig. 3(a). The elastic constant of AlN has significantly larger contributions than those of $\mathrm{Ru}$ and $\mathrm{Cr}$. However, for 3rd $(\sim 12 \mathrm{GHz})$ and 6 th $(\sim 22 \mathrm{GHz})$ modes, for example, the contributions of $\mathrm{Ru}$ and $\mathrm{Cr}$ become larger. We calculate the strain-energy distributions of the 1st, 3rd, and 6th modes as shown in Fig. 3(b). Strain energy of the 1st mode is larger in the AlN layer, however, those of 3rd and 6th mode become larger in $\mathrm{Ru}$ and $\mathrm{Cr}$ layers. We integrate the strain energy and calculate the strain-energy ratio in each layer, which shows a linear correlation as shown in the inset in Fig. 3(b). Therefore, these modes are important to obtain reliable elastic constants of $\mathrm{Ru}$ and $\mathrm{Cr}$ in spite of the difficulties in detection.

From the least-square approach for measured and calculated resonance frequencies, we succeed in inversely determining the elastic constant of each layer within $4 \%$ standard deviations at most. The elastic constant of AlN has a small deviation of $0.58 \%(2.4 \mathrm{GPa})$ because of large contributions. Elastic constants of $\mathrm{Ru}$ and $\mathrm{Cr}$ have relatively larger deviations of $1.4-3.7 \%$, however, it is enough small because measurement errors are about $1-10 \%$ even for mono-layer metal films. ${ }^{21,57,58)}$ We confirm that our measurement and inverse calculation use enough num-



Fig. 4. (Color online) (a) The uncertainties of the elastic constants due to measurement errors in resonance frequencies calculated using 7 modes (up to $30 \mathrm{GHz}$, pink circle), 18 modes (up to $70 \mathrm{GHz}$, blue square), and 26 mode (up to $100 \mathrm{GHz}$, green diamond). Vertical dashed line shows the rms error in our measurement. 
22) H. Ogi, T. Shagawa, N. Nakamura, M. Hirao, H. Odaka, and N. Kihara, Phys. Rev. B 78, 134204 (2008).

23) T. Yokoyama, T. Nishihara, S. Taniguchi, M. Iwaki, Y. Satoh, M. Ueda, and T. Miyashita, Proc. IEEE Ultrason. Symp., 429 (2004).

24) M. Ueda, T. Nishihara, S. Taniguchi, T. Yokoyama, J. Tsutsumi, M, Iwaki, and Y. Satoh, Jpn. J. Appl. Phys. 46, $4642(2007)$.

25) T. Yokoyama, Y. Iwazaki, Y. Onda, T. Nishihara, and M. Ueda, Proc. IEEE Ultrason. Symp., 1382 (2013).

26) M. Ueda, M. Hara, S. Taniguchi, T. Yokoyama, T. Nishihara, K. Hashimoto, and Y. Satoh, Jpn. J. Appl. Phys. 47, 4007 (2008).

27) T. Yokoyama, Y. Iwazaki, Y. Onda, Y. Sasajima, T. Nishihara, and M. Ueda, Proc. IEEE Ultrason. Symp., 281 (2014).

28) D. B. Fraser and R. C. LeCraw, Rev. Sci. Instrum. 35, 1113 (1964).

29) A. Migliori, J. L. Sarrao, W. M. Visscher, T. M. Bell, M. Lei, Z. Fiskl, and R. G. Leisure, Physica B 183, 1 (1993).

30) I. Ohno, J. Phys. Earth 24, 355 (1976).

31) H. Ogi, K. Sato, T. Asada, and M. Hirao, J. Acoust. Soc. Am. 112, 2553 (2002).

32) K. Adachi, H. Ogi, N. Takeuchi, N. Nakamura, H. Watanabe, T. Ito, and Y. Ozaki, J. Appl. Phys. 124, 085102 (2018).

33) C. Thomsen, J. Strait, Z. Vardeny, H. J. Maris, and J. Tauc, Phys. Rev. Lett. 53, 989 (1984).

34) C. Thomsen, H. T. Grahn, H. J. Maris, and J. Tauc, Phys. Rev. B 34, 4129 (1986).

35) K. Tanigaki, H. Ogi, H. Sumiya, K. Kusakabe, N. Nakamura, M. Hirao, and H. Ledbetter, Nat. Commun. 4, 2343 (2013).

36) A. Nagakubo, A. Yamamoto, K. Tanigaki, H. Ogi, N. Nakamura, and M. Hirao, Jpn. J. Appl. Phys. 51, 07GA09 (2012).

37) A. Nagakubo, H. Ogi, H. Sumiya, K. Kusakabe, and M. Hirao, Appl. Phys. Lett. 102, 241909 (2013).

38) A. Nagakubo, M. Arita, H. Ogi, H. Sumiya, N. Nakamura, and M. Hirao, Appl. Phys. Lett. 108, 221902 (2016).

39) W. S. Capinski and H. J. Maris, Rev. Sci. Instrum. 67, 2720 (1996).

40) T. Tachizaki, T. Muroya, O. Matsuda, Y. Sugawara, D. H. Hurley, and O. B. Wright, Rev. Sci. Instrum. 77, 043713 (2006).

41) T. Tachizaki, O. Matsuda, A. A. Maznev, and O. B. Wright, Phys. Rev. B 81, 165434 (2010).

42) P. A. Elzinga, R. J. Kneisler, F. E. Lytle, Y. Jiang, G. B. King, and N. M. Laurendeau, Appl. Opt. 26, 4303 (1987).

43) M. S. Brown, G. J. Fiechtner, J. V. Rudd, D. A. Zimdars, M Warmuth, and J. R. Gord, Appl. Spectrosc. 60, 261 (2006).

44) R. Legrand, A. Huynh, S. Vincent, B. Perrin, and A. Lemaître, Phys. Rev. B 95, 014304 (2017).

$45)$ A. Bartels, F. Hudert, C. Janke, T. Dekorsy, and K. Köhler, Appl. Phys. Lett. 88, 041117 (2006).

46) A. Bartels, R. Cerna, C. Kistner, A. Thoma, F. Hudert, C. Janke, and T. Dekorsy, Rev. Sci. Instrum. 78, 035107 (2007).

47) H. Ogi, Y. Fukunishi, T. Omori, K. Hatanaka, M. Hirao, M. Nishiyama, and, Anal. Chem. 80, 5494 (2008).

48) K. Uehara, H. Ogi, and M. Hirao, Appl. Phys. Express 7, 025201 (2014).

49) A. Nagakubo, M. Arita, T. Yokoyama, S. Matsuda, M. Ueda, H. Ogi, and M. Hirao, Jpn. J. Appl. Phys. 54, 07HD01 (2015).

50) T. Yanagitani and M. Suzuki, Appl. Phys. Lett. 105, 122907 (2014).

51) M. Kazan, E. Moussaed, R. Nader, and P. Masri, Phys. Status Solidi C 4, 204 (2007).

$52)$ E. S. Fisher and D. Dever, Trans. Metal. Soc. Aime 239, 48 (1967).

53) B. K. D. Gairola and E. Kröner, Int. J. Eng. Sci. 19, 865 (1981).

54) D. I. Bolep and J. D. Klerk, Phys. Rev. 129, 1063 (19633).

55) N. Nakamura, H. Ogi, and M. Hirao, Acta Mater. 52, 765 (2004).
56) K. Adachi, H. Ogi, A. Nagakubo, N. Nakamura, M. Hirao, M. Imade, M. Yoshimura, and Y. Mori, Appl. Phys. Lett. 109, 182108 (2016).

57) N. Nakamura, H. Ogi, T. Shagawa, and M. Hirao, Appl. Phys. Lett. 92, 141901 (2008).

58) Y. C. Wen, Y. C. Liao, H. H. Chang, B. H. Mok, Y. C. Lee, T. W. Huang, K. W. Yeh, J. Y. Luo, M. J. Wang, C. K. Sun, and M. K. Wu, J. Appl. Phys. 110, 073505 (2011).

59) Y. Abe, Y. Kaga, M. Kawamura, and K. Sasaki, Jpn. J. Appl. Phys. 40, 6956 (2001).

$60)$ N. Nakamura, Y. Nakamichi, H. Ogi, M. Hirao, and M. Nishiyama, Jpn. J. Appl. Phys. 52, 07 HB05 (2013).

61) K. Kim, M. Park, W. Lee, H. W. Kim, J. G. Lee, and C. Lee, Mater. Sci. Technol. 24, 838 (2008).

62) T. P. Harzer, S. Djaziri, R. Raghavan, and G. Dehm, Acta Mater. 83, 318 (2015). 